\title{
Rizobacterias promotoras de crecimiento en Guarianthe skinneri (Orchidaceae)
}

\author{
Trinidad Aguilar Díaz ${ }^{1}$, Vincenzo Bertolini ${ }^{1 *}$, Guillermo Carrillo Castañeda ${ }^{2}$, \\ Griselda Karina Guillén Navarro ${ }^{1}$, Luz Verónica García Fajardo ${ }^{1}$ \\ \& Ricardo Alberto Castro Chan ${ }^{1}$ \\ 1. El Colegio de la Frontera Sur, Carretera Antiguo Aeropuerto Km 2.5, C.P. 30700 Tapachula, Chiapas, México; \\ traguilar@ecosur.edu.mx, vin.bertolini@gmail.com; kguillen@ecosur.mx, lvgarcia@mail.ecosur.mx, \\ rcastro@ecosur.mx \\ 2. Colegio de Postgraduados, Campus Montecillo, Carretera México-Texcoco Km. 36.5, Estado de México 56230; \\ carrillo@colpos.mx \\ * Correspondencia
}

Recibido 10-V-2018. Corregido 25-V-2018. Aceptado 26-VI-2018.

\begin{abstract}
Growth-promoting rhizobacteria from Guarianthe skinneri (Orchidaceae). The Guarianthe skinneri orchid is included in NOM-059-ECOL-2010, Mexico standard as an endangered species. In order to study PGPR (promoting growth plant rhizobacteria) from this orchid, 10 roots were collected from different plants to isolate bacteria associated with the roots, which were analyzed by in vitro tests such as: production of AIA, nitrogen fixation, interaction with the mycorrhizal fungus Thanatephorus sp. strain RG26 and phosphate solubilization. We obtain 71 bacterial isolates, 10 strains of them were characterized by sequencing the 16s rDNA marker identifying six bacteria: Sphingomonas sp., Sinorhizobium sp., Bacillus sp., Nocardia cerradoensis, Bacillus megaterium, and Burkholderia phytofirmans. We observed that the bacterium Sinorhizobium sp. produced a greater amount of AIA $(69.189 \mu \mathrm{g} / \mathrm{ml})$ and Bacillus sp. performed greater acetylene reduction $(10.251$ $\mathrm{nmol} / 96 \mathrm{~h}$ ). In the interactions of the bacteria and the fungus RG26, four categories were presented (extremely positive, positive, antagonism 50-50 and inhibition). In relation to the solubilization of phosphate, Burkholderia phytofirmans presented higher IS after 48 and $96 \mathrm{~h}$ with an IS of 3.11 and 3.48, respectively. The results indicate that Bacillus sp. could have the best characteristics to promote the development of the G. skinneri orchid by inoculating seeds and seedlings.
\end{abstract}

Key words: Bacillus sp.; antagonism; indoleacetic acid; phosphate solubilization; nitrogen fixation.

Aguilar Díaz, T., Bertolini, V., Carrillo Castañeda, G., Guillén Navarro, G. K., García Fajardo, L. V., \& Castro Chan, R. A. (2018). Rizobacterias promotoras de crecimiento en Guarianthe skinneri (Orchidaceae). Revista de Biología Tropical, 66(3), 953-968.

El estado de Chiapas (México) se caracteriza por su amplia biodiversidad. En particular la familia Orchidaceae es una de las más abundantes con 700 especies de orquídeas aproximadamente (Solano-Gómez et al., 2016). La región del Soconusco hospeda en su territorio 105 géneros y 325 especies de orquídeas, representando el $24 \%$ de la riqueza orquideológica nacional (Solano-Gómez et al., 2016). Una de las orquídeas más apreciadas en la región del Soconusco es Guarianthe skinneri (Bateman) Dressler \& W. E. Higgins, una orquídea epífita nativa del Sureste de México, América Central y Sur de Costa Rica (Bechtel, Cribb, \& Launert, 1992; Bertolini, Damon, \& Ibarra-Cerdeño, 2016). Es conocida como 
guaria morada y candelaria (Vargas-Zamora \& Gómez-Laurito, 2005; Semarnat, 2010). Esta planta se puede encontrar en intervalos de distribución altitudinal desde 100-1 000 msnm (Damon \& Colín-Martínez, 2004). La orquídea G. skinneri anteriormente estaba incluida en el género de las Cattleya, pero recientemente y tras análisis de filogenia molecular se incluyó en el género Guarianthe (Dressler \& Higgins, 2003). Florece en los meses de febrero y mayo en la estación seca (Vargas-Zamora \& GómezLaurito, 2005) durante las fechas de la fiesta religiosa de la Candelaria, siendo esta la razón de la reducción de sus poblaciones silvestres por la excesiva recolecta para fines ceremoniales (Bogarín \& Pupulin, 2007). Además de esto, la deforestación, la destrucción de su hábitat, la apertura de campos agrícolas y los incendios forestales entre otros, ha llevado a la especie casi a la desaparición en su hábitat natural. Por estas razones la orquídea $G$. skinneri está presente en la lista NOM-059ECOL-2010 como una especie amenazada en México (Semarnat, 2010).

La biología reproductiva de las orquídeas es compleja, desde la polinización hasta la germinación de las semillas, que requiere de un simbionte micorrízico para germinar en el medio natural (Yoder, Zettler \& Stewart, 2000). La presencia de estos microorganismos es favorecida por los exudados radiculares de la orquídea altamente nutritivos, que actúan como atrayentes químicos de múltiples especies de bacterias y micorrizas (Ahemad \& Kibret, 2014; Prashar, Kapoor, \& Sachdeva, 2014). Se han aislado bacterias benéficas a partir de las raíces de diversas orquídeas, muchas de estas presentan la capacidad de producir ácido indolacético (AIA) como Burkholderia sp., Bacillus sp., Pseudomonas sp., y Agrobacterium sp., (Tsavkelova, Cherdyntseva, Botina, \& Netrusov, 2007a), Bacillus sp., Burkholderia sp., Enterobacter sp., y Curtobacterium sp., (Galdiano-Júnior, Pedrinho, Castellane, \& Lemos, 2011), Paenibacillus sp., (Faria, Dias, Melo, \& Carvalho-Costa, 2013). Al igual bacterias fijadoras de nitrógeno (Zambrano-Ramos, Salgado-Jiménez, \& Hernández-Tapia, 2007;
Álvarez-López, Osorio-Vega, Díez-Gómez, \& Martín-Montoya, 2014; Yang et al., 2014; Villegas-Espinoza et al., 2014; Li et al., 2017). Se han reportado otras bacterias solubilizadoras de fosfato inorgánico como Serratia sp. y Pseudomonas koreensis (Álvarez-López et al., 2014). Las asociaciones de hongos, bacterias y cianobacterias forman junto con las raíces de orquídeas un vasto y complejo microhábitat (Tsavkelova, Lobakova, Kolomeitseva, Cherdyntseva, \& Netrusov, 2003). Algunas bacterias presentan interacciones benéficas con hongos endófitos mejorando el crecimiento de las plántulas in vitro (Wang et al., 2016), como también la germinación de semillas y el crecimiento de plántulas de orquídeas en la aclimatación ex vitro (Tsavkelova et al., 2007a; Galdiano-Júnior et al., 2011; Faria et al., 2013).

El objetivo del presente estudio fue identificar, caracterizar bioquímicamente y mediante secuenciación de 16s DNAr cepas bacterianas asociadas a las raíces de la orquídea G. skinneri con potencial para el crecimiento vegetal que puedan considerarse como Bacterias Promotoras de Crecimiento Vegetal (BPCV).

\section{MATERIALES Y MÉTODOS}

Aislamiento y purificación de cultivos bacterianos: Se aislaron bacterias a partir de 10 muestras de raíces con características fitosanitarias sanas de individuos de G. skinneri provenientes de la colección del Jardín Botánico Regional del Soconusco, Tuzantán, Chiapas, México. Se obtuvieron segmentos de ápices de raíces en crecimiento, de aproximadamente 3 $\mathrm{cm}$ de longitud y se trasportaron del sitio de colecta hasta las instalaciones de laboratorio de la unidad de Tapachula de Ecosur (El Colegio de la Frontera Sur), empleando una mochila térmica paras su conservación en frío durante el traslado. Para obtener las bacterias asociadas a las raíces se procedió a procesar cada raíz en ambiente estéril depositando los fragmentos en tubos de ensayo con $2 \mathrm{ml}$ de agua estéril, que fue agitado enérgicamente con un vortex en 2 períodos de 1 min cada uno, para obtener la suspensión bacteriana; en seguida se depositaron 
los fragmentos de raíz en otros tubos con $5 \mathrm{ml}$ de agua estéril con la finalidad de dar un lavado suave para colocarlas posteriormente en un tubo con $1 \mathrm{ml}$ de agua estéril, donde, con una varilla de vidrio estéril, se maceraron para obtener la suspensión bacteriana a estudiar. Con una asa bacteriológica estéril se tomó una alícuota de la suspensión bacteriana del primer tubo y del último tubo para hacer estrías en medio de cultivo sólido B de King en placas Petri de $100 \cdot 15$ mm (King, Ward, \& Raney, 1954). Previamente, la superficie del medio de cultivo fue dividida en dos áreas ( $\mathrm{a}$ y b) para estriar dos muestras en cada placa Petri del mismo tubo. Las placas se colocaron en incubadoras (Blue M 200A Stabil-Therm) a $28{ }^{\circ} \mathrm{C}$ durante $48 \mathrm{~h}$. Las colonias fueron re-aisladas y cultivadas en tubos de ensayo inclinados, conteniendo cada uno $2 \mathrm{ml}$ de medio de cultivo sólido B de King, por estría cruzada. Todas las colonias se conservaron en glicerol al $30 \%$ de acuerdo al protocolo de Carrillo, Puente, Castellanos y Bashan (1998), realizando cuatro réplicas por cada cepa y fueron conservadas en congelación a $-20{ }^{\circ} \mathrm{C}$.

Síntesis de Ácido indolacético (AIA): Las bacterias se inocularon por triplicado en tubos viales de $22 \mathrm{ml}$ conteniendo $15 \mathrm{ml}$ del medio de cultivo Czapek suplementando con $200 \mu \mathrm{g} / \mathrm{ml}$ de DL-triptófano (SIGMA) y posteriormente se incubaron en oscuridad a $28{ }^{\circ} \mathrm{C}$, en agitación constante en Maxi-Shake (SBD PL 50 BIO) a $150 \mathrm{rpm}$ durante $72 \mathrm{~h}$. Concluidas las $72 \mathrm{~h}$ se tomó $1 \mathrm{ml}$ de cultivo bacteriano que fue transferido a tubos viales de $22 \mathrm{ml}$ conteniendo $15 \mathrm{ml}$ de cultivo Czapek suplementado con $200 \mu \mathrm{g} / \mathrm{ml}$ de DL-triptófano (SIGMA), manteniéndolas en oscuridad a 28 ${ }^{\circ} \mathrm{C}$ en agitación constante a $150 \mathrm{rpm}$ por $48 \mathrm{~h}$ (Tsavkelova, Cherdyntseva, Lobakova, Kolomeitseva, \& Netrusov, 2001; Tsavkelova, Cherdyntseva, \& Netrusov, 2005). Transcurrido ese tiempo, se tomó $1.5 \mathrm{ml}$ del cultivo bacteriano que fue depositado en microtubos estériles de $1.5 \mathrm{ml}$, para centrifugarlos a $7000 \mathrm{xg}$ durante 10 min (centrifuga HERMLE Z 233 M-2). Se recolectó $1 \mathrm{ml}$ del sobrenadante por cada cepa y se colocaron respectivamente en tubos de ensayo de vidrio de 12 x $100 \mathrm{~mm}$ (Tsavkelova et al., 2007; Galdiano-Júnior et al., 2011). Se agregaron $2 \mathrm{ml}$ de solución Salkowski (35\% de $\mathrm{HClO}_{4}+1 \mathrm{ml} \mathrm{de} \mathrm{FeCI}_{3} 0.5 \mathrm{M}$ ) (Gordon \& Weber, 1951). La mezcla se mantuvo 30 min en oscuridad, observando tonos de coloración entre rosado a fucsia que corresponden a altas cantidades de moléculas de indol. La intensidad del color se midió por absorbancia a $530 \mathrm{~nm}$ en un espectrofotómetro (Shimadzu UV-1700). Los resultados obtenidos fueron calculados a partir de una curva de calibración realizada a partir de un stock de $100 \mu \mathrm{g} / \mathrm{ml}$, $(0,2,4,6,8,10,15,20,30,40,50$ y $60 \mu \mathrm{g} /$ $\mathrm{ml})$ de AIA grado reactivo de la marca Aldrich (No. Cat. I3750) obteniendo así la ecuación $\mathrm{y}=0.0104 \mathrm{x}+0.0291$, con un $\mathrm{R}^{2}=0.9821$ (Mantilla-Cardenas, 2007).

Análisis molecular de las bacterias: Se extrajo el ADN de las bacterias mediante el Kit Aqua Pure Genomic DNA (Bio-Rad No. Cat. 732-6340). Se realizó PCR dirigido a la región $16 \mathrm{~S}$ ADN ribosomal por medio de los primers fD1 (directo) (5' AGAGTTTGATCCTGGCTCAG 3') y rD1 (reverso) (5' AAGGAGGTGATCCAGCC 3') (Weisburg, Barns, Pelletier, \& Lane, 1991) que amplifican un fragmento de aproximadamente $1500 \mathrm{pb}$, abarcando las nueve regiones hipervariables del gen 16S ribosomal, según el modelo de Escherichia coli (Chakravorty, Helb, Burday, Connell, \& Alland, 2007). La amplificación se llevó a cabo utilizando $1 \mu \mathrm{L}$ de $\mathrm{ADN}$; por cada muestra se utilizaron las siguientes concentraciones finales de soluciones: Buffer para PCR (1X), $0.2 \mathrm{mM}$ de dNTP's, $0.2 \mathrm{pM}$ de cada

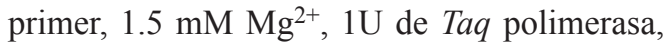
en un volumen final de $25 \mu \mathrm{L}$. Las condiciones de ciclos y temperatura fueron las siguientes: primer ciclo inicial de desnaturalización $94^{\circ} \mathrm{C}$ por $5 \mathrm{~min}$, seguido de 35 ciclos de desnaturalización a $94{ }^{\circ} \mathrm{C}$ por $30 \mathrm{~s}$, alineamiento $53{ }^{\circ} \mathrm{C}$ por $30 \mathrm{~s}$, extensión $72{ }^{\circ} \mathrm{C}$ por 1 min y una extensión final a $72{ }^{\circ} \mathrm{C}$ por $10 \mathrm{~min}$. Obtenidos los productos de PCR se purificaron mediante el Kit Quantum Prep ${ }^{\circledR}$ PCR Kleen Columns 
(Bio-Rad, No. Cat. 732-6300) y posteriormente se enviaron a Macrogen Inc. (Seúl, Corea) para su secuenciación. Los resultados se analizaron utilizando el algoritmo tipo Blast y la base de datos del Genebank (https://www.ncbi.nlm.nih. gov/). Las distancias evolutivas se calcularon utilizando el método de máxima Similitud, basado en el modelo de Kimura con dos parámetros (Kimura, 1980). Se muestra el árbol con el máximo valor logarítmico de similitud (-228.64). El porcentaje de árboles al cual los taxa asociados se agrupan se muestra junto a las ramas. Los árboles iniciales para la búsqueda heurística se obtuvieron automáticamente aplicando los algoritmos de Neighbor-Joining y BIONJ a una matriz de distancias que se estimó utilizando la aproximación de Similitud Máxima compuesta (MLC), y posteriormente se seleccionó la topología con mayor valor logarítmico de similitud. Se utilizó una distribución Gamma discreta para modelar las diferencias evolutivas entre los sitios (5 categorías $(+\mathrm{G}$, parámetro $=0.4061)$ ). El árbol está dibujado a escala, en donde la longitud de las ramas está medida con base en el número de sustituciones por sitio. El análisis involucró 33 secuencias de nucleótidos. Todas las posiciones que contienen gaps y datos faltantes fueron eliminadas, de modo que se tuvo un total de 63 posiciones en el conjunto de datos final (Kumar, Stecher, \& Tamura, 2016).

Prueba de reducción de acetileno: En frascos serológicos de $100 \mathrm{ml}$ conteniendo 40 $\mathrm{ml}$ del medio de cultivo Rennie (1981) semisólido al $0.2 \%$, se agregó $1 \mathrm{ml}$ de suspensión bacteriana de cada aislado, posteriormente se tapó y se selló, retirando $1 \mathrm{ml}$ de aire y reemplazando con la misma cantidad de acetileno, colocando los frascos a $25 \pm 2{ }^{\circ} \mathrm{C}$ durante cuatro días. Para validar los resultados se usó como control positivo la bacteria Sinorhizobium meliloti 1021 (Jones, Kobayashi, Davies, Taga, \& Walker, 2007). La bacteria S. meliloti 1021 fue donada a Ecosur, por el cepario del Centro de Ciencias Genómicas de la Universidad Nacional Autónoma de México (anteriormente "Centro de Investigación sobre Fijación de
Nitrógeno"). La reducción de acetileno a etileno se determinó por cromatografía de gases de acuerdo a Hardy, Holsten, Jackson y Burns (1968), inyectando $5 \mu \mathrm{l}$ de gas de las muestras en el cromatógrafo de gases (Clarus ${ }^{\circledR} 500$ PerkinElmer $\left.{ }^{\circledR}\right)$, las condiciones del cromatógrafo fueron las siguientes: temperatura del inyector y detector $200{ }^{\circ} \mathrm{C}$, las condiciones del horno se muestran en el apéndice digital 1, con tasas de flujo de aire de $300 \mathrm{ml} / \mathrm{min}$ y de hidrógeno $30 \mathrm{ml} / \mathrm{min}$, se utilizó una columna GS-AL/KCI de $50 \mathrm{~m}$ de largo con $0.530 \mathrm{~mm}$ de diámetro y un detector de ionización de llama (FID). Los resultados obtenidos fueron calculados mediante la ecuación $\mathrm{y}=12.241 \mathrm{X}+5.0513$, con un $\mathrm{R}^{2}=0.9757$, a partir de una curva realizada por triplicado en el cromatógrafo de gases (10.694, $13.368,16.042,18.715,26.737,37.431,53.474$ nmol) de un estándar de nitrógeno conteniendo 15 ppm de diferentes gases (Supelco, No. Cat. 22566). A los datos obtenidos en la prueba de fijación de nitrógeno se aplicó una prueba no paramétrica Kruskal-Wallis y la prueba de Tukey $(\mathrm{P}<0.05)$ mediante el software estadístico R versión 3.1.2 (R Core Team, 2013).

Compatibilidad de las bacterias con la micorriza orquidiode RG26 (cepas conservadas en el laboratorio de ecología cultivo sustentable de las orquídeas del Soconusco, Ecosur, unidad Tapachula): Se evaluó la interacción in vitro de las cepas bacterianas con el hongo micorrízico Thanatephorus sp., cepa RG26 (López-Chávez, Guillén-Navarro, Bertolini, Encarnación, Hernández-Ortiz, SánchezMoreno y Damon, 2016), aislado a partir de Rossioglossum grande (Lindl.) Garay \& G.C. Kenn. y que presentó resultados exitosos en la germinación y desarrollo de protocormos in vitro de Rhynchostele bictoniensis (Bateman) Soto Arenas \& Salazar (Bertolini, Damon, \& Rojas-Veláquez, 2011), de Oncidium sphacelatum Lindl. (López-Chávez et al., 2016) y Guarianthe skinneri (Bateman) Dressler \& W.E. Higgins (datos no publicados). En el caso de Oncidium sphacelatum Lindl, los análisis proteómicos realizados han evidenciado que la presencia del hongo micorrízico involucra 
proteínas, reciclaje de purinas, biogénesis de ribosomas durante de desarrollo de los protocormos de la orquídea (López-Chávez et al., 2016). En este sentido, se usó el hongo micorrízico para evaluar las interacciones con los aislados bacterianos que pudieran dar más enfoques de su comportamiento e interrelación. Para ello el hongo RG26 fue cultivado en placas Petri de $100 \cdot 15 \mathrm{~mm}$, conteniendo el medio sólido B de King (King et al., 1954) por 13 días a $25^{\circ} \mathrm{C}$. Posteriormente, se extrajo un fragmento de este cultivo agarizado de la micorriza RG26 para inocular el centro en una placa Petri de $9 \mathrm{~cm}$ de diámetro con cultivo virgen. Transcurridas $24 \mathrm{~h}$ se inocularon 4 diferentes aislados bacterianos en cada punto diagonal de la placa Petri, a una distancia de 3 $\mathrm{cm}$ del centro de la placa. Se midió también el crecimiento del hongo micorrízico en una caja Petri sin inocular, para validar los resultados de crecimiento de la micorriza RG26 con y sin colonia bacteriana (Macedo, Martínez y Lara, 2012). Las placas Petri fueron colocadas a una temperatura de $25^{\circ} \mathrm{C}$. Transcurridas las $48 \mathrm{~h}$ se tomaron fotografías cada $24 \mathrm{~h}$, evaluando el crecimiento del hongo hacia las bacterias durante 15 días. La prueba de compatibilidad se realizó de acuerdo a Wang et al. (2016) donde se establecieron tres tipos de interacciones, siendo: positivo, letal y antagonismo, sin embargo en las pruebas de los aislados bacterianos con el hongo micorrízico RG26 se realizaron algunas modificaciones para establecer cuatro categorías siendo las siguientes: sumamente positivo $(++)$ cuando el crecimiento del hongo se sobrepone cubriendo a toda la colonia bacteriana sin tener algún efecto negativo; positivo $(+)$ cuando el hongo micorrízico y la colonia bacteriana están juntas pero el hongo crece lentamente sobre la colonia bacteriana; antagonismo 50-50 (0) cuando ambos interrumpen su crecimiento sin que uno prevalezca sobre el otro y, por último, inhibición (-) cuando las bacterias inhiben el crecimiento del hongo micorrízico.

Solubilización de fosfato inorgánico: Los aislados bacterianos se sometieron a la solubilización del fosfato de calcio tribásico $\left(\mathrm{Ca}_{3} \mathrm{P}_{2} \mathrm{O}_{8}\right)$, utilizando el medio SRS (SundaraRao \& Sinha, 1963), en placas Petri de $100 \bullet 15$ mm empleando la metodología de Carrillo et al. (1998). Para obtener el inóculo, en tubos viales de $22 \mathrm{ml}$ conteniendo $15 \mathrm{ml}$ de cultivo líquido $\mathrm{B}$ de King se sembró una parte de la colonia bacteriana, realizando cuatro réplicas de cada bacteria, los tubos se colocaron en el agitador a 150 rpm a $28{ }^{\circ} \mathrm{C}$ durante tres días. Por cada placa Petri se inocularon cuatro bacterias diferentes con un inóculo de $10 \mu \mathrm{l}$ de cultivo bacteriano. Las placas se incubaron a $25^{\circ} \mathrm{C}$, se tomaron fotografías de cada placa a las 48 y $96 \mathrm{~h}$ para posteriormente procesar las imágenes en el programa ImageJ 1.44 (http://rsbweb.nih.gov/ij/), considerado el diámetro de la colonia bacteriana y diámetro del halo en $\mathrm{mm}$, evaluando positivas las bacterias cuando el indicador púrpura de bromocresol del medio de cultivo cambia de morado a amarillo. Posteriormente se determinó el índice de solubilización (IS) de acuerdo a la fórmula IS $=\mathrm{A} / \mathrm{B}$ donde $\mathrm{A}=$ diámetro (colonia $\mathrm{mm}+$ halo amarillo $\mathrm{mm}$ ) y B = diámetro de la colonia mm (Kumar \& Narula, 1999).

\section{RESULTADOS}

Se obtuvieron un total de 71 aislados bacterianos asociados a las raíces de la orquídea G. skinneri, que presentaron características morfológicas diferentes (Fig. 1).

Síntesis de AIA: Diez bacterias fueron seleccionadas por presentar índices mayores de producción de AIA. Se observó que la bacteria que presentó mayor producción de AIA fue Sinorhizobium sp., (cepa 1-7c) con 69.189 $\mu \mathrm{g} / \mathrm{ml}$ y la que presentó menor producción de AIA Bacillus sp., (cepa 1-10d) con $10.18 \mu \mathrm{g} /$ $\mathrm{ml}$ (Apéndice digital 2). La producción de AIA es una de las características propias de algunas bacterias que son consideradas como BPCV.

Identificación molecular de las bacterias: De las 10 bacterias seleccionadas, se logró la purificación y secuenciación del material genético de seis de ellas $(1-4 c, 1-7 \mathrm{c}, 1-10 \mathrm{~d}$, 


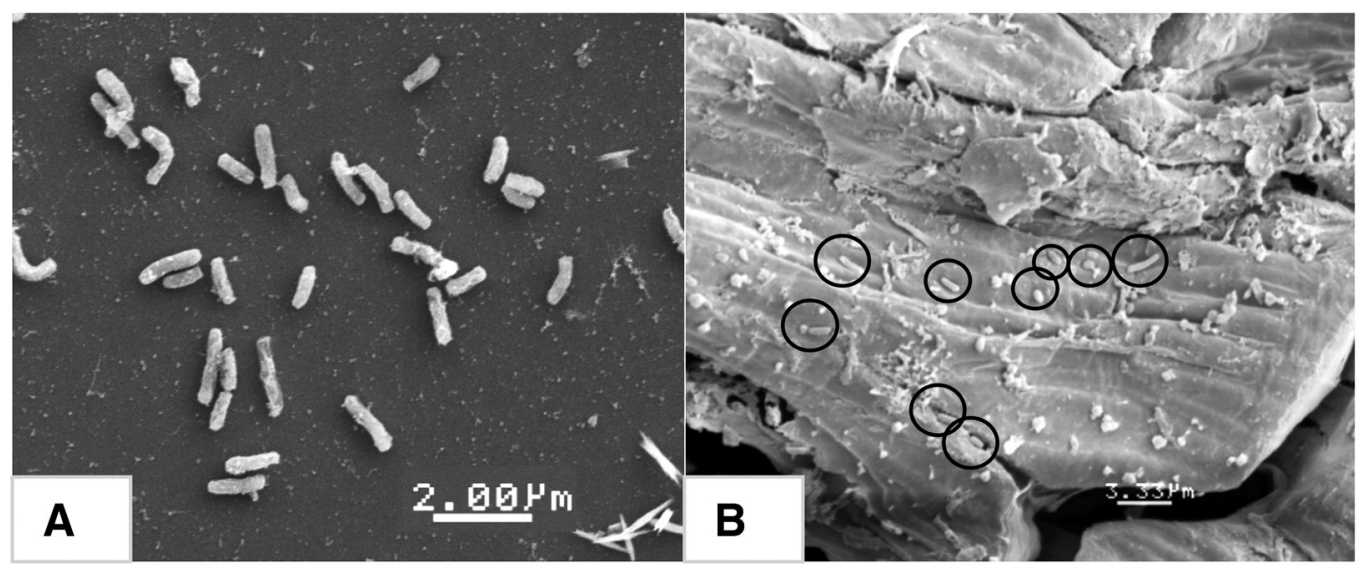

Fig. 1. A) Morfología bacteriana de Sinorhizobium sp. analizada en el Microscopio Electrónico de Barrido (MEB) y B) Morfotipos bacterianos presentes en las raíces de la orquídea G. skinneri.

Fig. 1. A) Bacterial morphology of Sinorhizobium sp. analyzed in the Scanning Electron Microscope (SEM) and B) Bacterial morphotypes present in the roots of the G. skinneri orchid.

$2-7 \mathrm{a}, 2-10 \mathrm{~b}$ y $2-10 \mathrm{bp})$. En la base de datos de GenBank se logró identificar el género y especie de algunas bacterias. La bacteria 1-4c tuvo un $99 \%$ de homología con Sphingomonas sp. (número de acceso JQ766118.1), la bacteria 1-7c tuvo una homología de $100 \%$ como Sinorhizobium sp. (número de acceso DQ987860.1), la bacteria 1-10d fue $99 \%$ homóloga a Bacillus sp. (número de acceso KT151923.1), la bacteria 2-7a tuvo $100 \%$ de homología con Nocardia cerradoensis (número de acceso KM978282.1), la bacteria 2-10b presentó una homología de $100 \%$ con Bacillus megaterium (número de acceso KX023249.1) y la bacteria 2-10bp tuvo $99 \%$ de homología con Burkholderia phytofirmans (número de acceso CP001053.1) (Apéndice digital 2).

La figura 2 muestra el agrupamiento de las secuencias de los genes ribosomales $16 \mathrm{~S}$ de las cepas bacterianas aisladas 1-4c (Sphingomonas sp.), 1-7c (Sinorhizobium sp.), 1-10d (Bacillus sp.) 2-7a (Nocardia cerradoensis), 2-10b (Bacillus megaterium) y 2-10bp (Burkholderia phytofirmans) con las secuencias más cercanas identificadas en las bases de datos GenBank. El aislado 1-4c se agrupó en una rama muy compacta soportada con un valor de bootstrap de 55/100 junto con organismos del género Sphingomonas, si bien no nos permitió determinar con certeza la especie del aislado bacteriano, únicamente nos posibilitó determinar que es un organismo del género Sphingomonas. Por otro lado el aislado 1-7c se agrupó en una rama soportado con un valor de bootstrap de 61/100, agrupándose al género Sinorhizobium pero no fue posible precisar la especie; ambos pertenecientes al grupo alpha-Proteobacteria. La cepa 2-10bp se agrupó al racimo soportado con valor de bootstrap 65/100, al grupo Burkholderia en la que no fue posible identificar la especie pero si al género que pertenece y al grupo beta-proteobacteria. Las cepas 1-10d y 2-10b se agruparon en un racimo del árbol que fue soportado con valores de bootstrap de 86/100 junto con el género de Bacillus, sin embargo no fue posible determinar la especie a la que pertenece, concluyendo que ambos pertenecen al grupo Firmicutes y por último el aislado 2-7a se agrupó en un racimo soportado con un valor de bootstrap de 64/100 al género Nocardia, con el resultado obtenido no fue posible precisar la especie, concluyendo que pertenece al grupo Actinobacteria.

Prueba de reducción de acetileno: Los resultados obtenidos muestran que las 10 bacterias tuvieron la capacidad de reducir el acetileno. Se encontró que Bacillus sp. presentó 


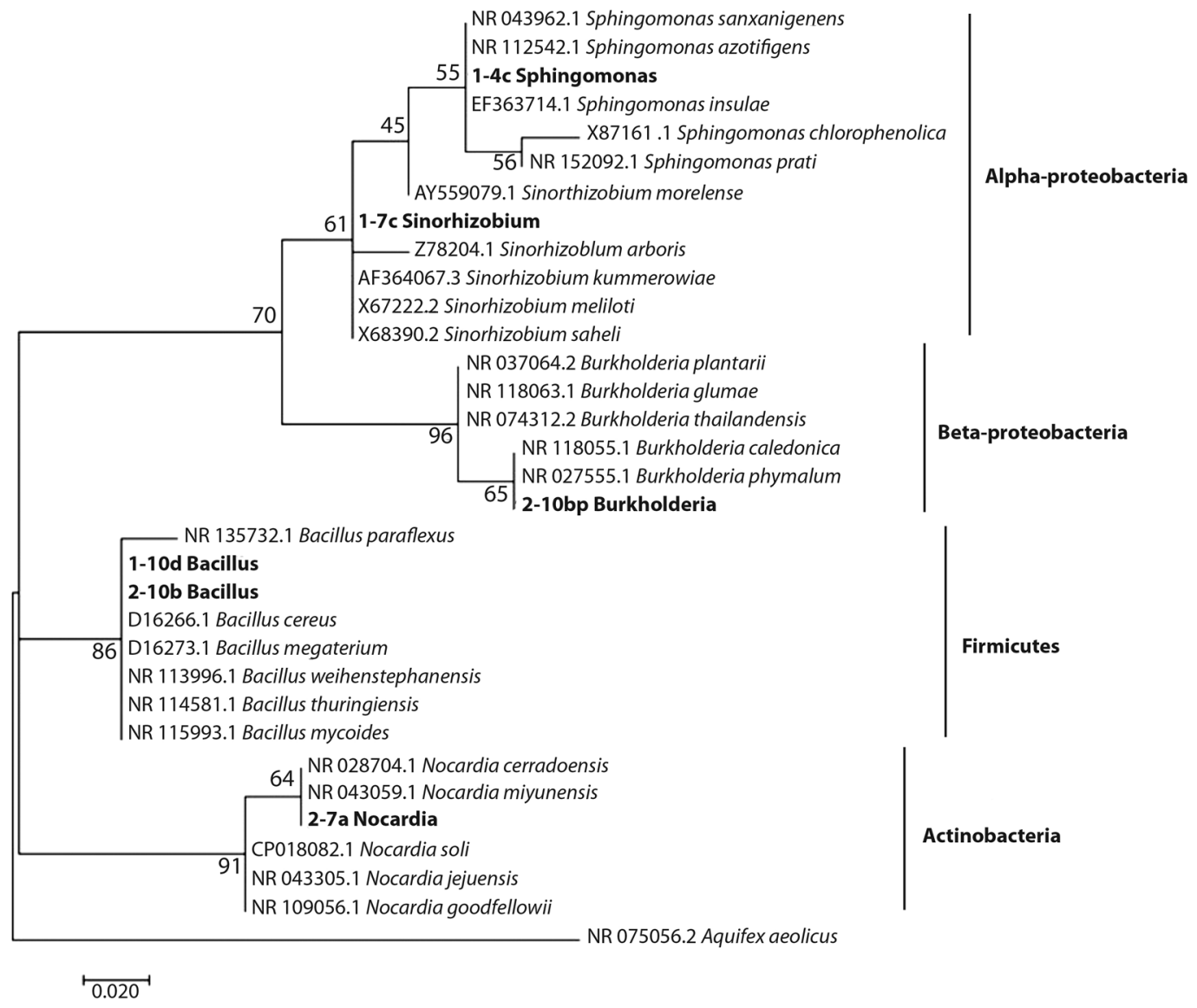

Fig. 2. Análisis filogenético molecular por el método de Máxima Similitud.

Fig. 2. Molecular phylogenetic analysis by the Maximum Similarity method.

mayor reducción con $10.251 \mathrm{nmol}$ cultivo/96 h, mientras que Sinorhizobium sp., presentó menor reducción con $1.637 \mathrm{nmol}$ cultivo/96 h. Respecto al control positivo S. meliloti 1021, presentó un valor de $4.920 \mathrm{nmol}$ cultivo/96 h, encontrando así diferencias con las bacterias aisladas (Apéndice digital 2).

\section{Compatibilidad de las bacterianas con} el hongo micorrízico Thanatephorus sp., RG26: En los resultados obtenidos en términos de compatibilidad in vitro de las bacterias con el hongo micorrízico RG26 se presentaron las cuatro categorías establecidas. De los aislados se obtuvo que Bacillus sp. y N. cerradoensis presentaron la categoría sumamente positiva, y las cepas 2-6d, 2-8d y B. megaterium con la categoría positiva, mientras que las cepas 1-6a, 2-9b, B. phytofirmans y Sinorhizobium sp. presentaron respuesta de antagonismo 50-50 y Sphingomonas sp. se mostró inhibidora del hongo micorrízico (Fig. 3 y Apéndice digital 2).

Solubilización de fosfato inorgánico: Se encontró que las 10 bacterias varían en grado de IS de acuerdo al halo observado, se obtuvo que $B$. phytofirmans presentó mayor IS a las 48 y 96 h con IS de 3.11 y 3.48 , seguido $B$. megaterium con un IS de 2.66 a las $48 \mathrm{~h}$ y a las 96 h con 2.84 (Fig. 4), mientras que la cepa Sphingomonas sp. no presentó IS a pesar de crecer en el medio de cultivo, no hubo evidencia de su capacidad de solubilizar el fosfato. La bacteria Bacillus sp., no presentó IS a las $48 \mathrm{~h}$ 

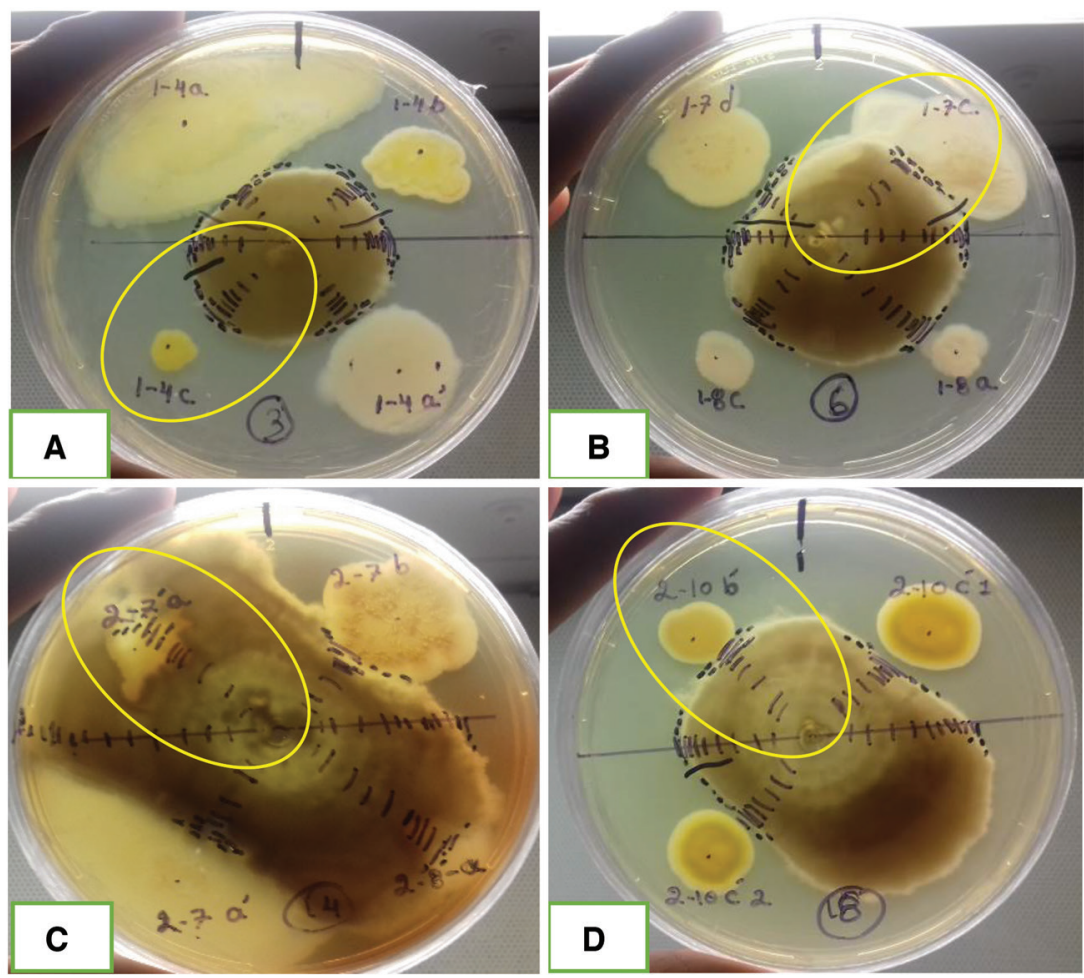

Fig. 3. Ejemplo de interacción de las cepas bacterianas con el hongo micorrízico RG26. A) Cepa 1-4c (Sphingomonas sp.) inhibición, B) cepa 1-7c (Sinorhizobium sp.) antagonista 50-50, C) cepa 2-7a (Nocardia cerradoensis) Sumamente positiva y la cepa 2-10bp (Burkholderia phytofirmans) antagonista 50-50.

Fig. 3. Example of interaction of the bacterial strains with the mycorrhizal fungus RG26. A) strain 1-4c (Sphingomonas sp.) inhibition, B) strain 1-7c (Sinorhizobium sp.) Antagonist 50-50, C) strain 2-7a (Nocardia cerradoensis) Highly positive and strain 2-10bp (Burkholderia phytofirmans) 50-50 antagonist.

si no que hasta las 96 h se observó el IS con 2.31 (Apéndice digital 2).

\section{DISCUSIÓN}

En las raíces de la orquídea G. skinneri se obtuvieron diferentes aislamientos bacterianos que presentaban diferentes características morfológicas. Tsavkelova et al. (2003) mencionan que la diversidad de bacterias, hongos y cianobacterias forman un consorcio asociado a la planta huésped, que puede ser útil en el proceso de desarrollo de las orquídeas. También se ha mostrado que los aislados bacterianos varían en relación a las especies de orquídeas y las zonas de la planta donde se aíslan. Por ejemplo, Zambrano-Ramos et al. (2007) obtuvieron en
Laelia furfuracea Lindl., 67 cepas de bacterias y en Oncidium sphacelatum Lindl., 81 cepas de bacterias, mientras que Faria et al. (2013) obtuvieron un menor número de aislados (solamente 12). Prashar et al. (2014) mencionan que la mayoría de los microorganismos, aproximadamente el $99 \%$, no son cultivables. Esto se debe a que las comunidades de bacterias tienen un micro hábitat muy peculiar que depende de la especie hospedera, el tipo de raíz y la composición de los exudados radiculares (Tsavkelova et al., 2007a) y además presentan una amplia diversidad de compuestos orgánicos (Dakora \& Phillips, 2002; Hartmann, Schmid, van Tuinen y Berg, 2009).

Con relación a la producción de AIA se encontró que las bacterias tienen la capacidad de producir esta hormona, detectando que el 


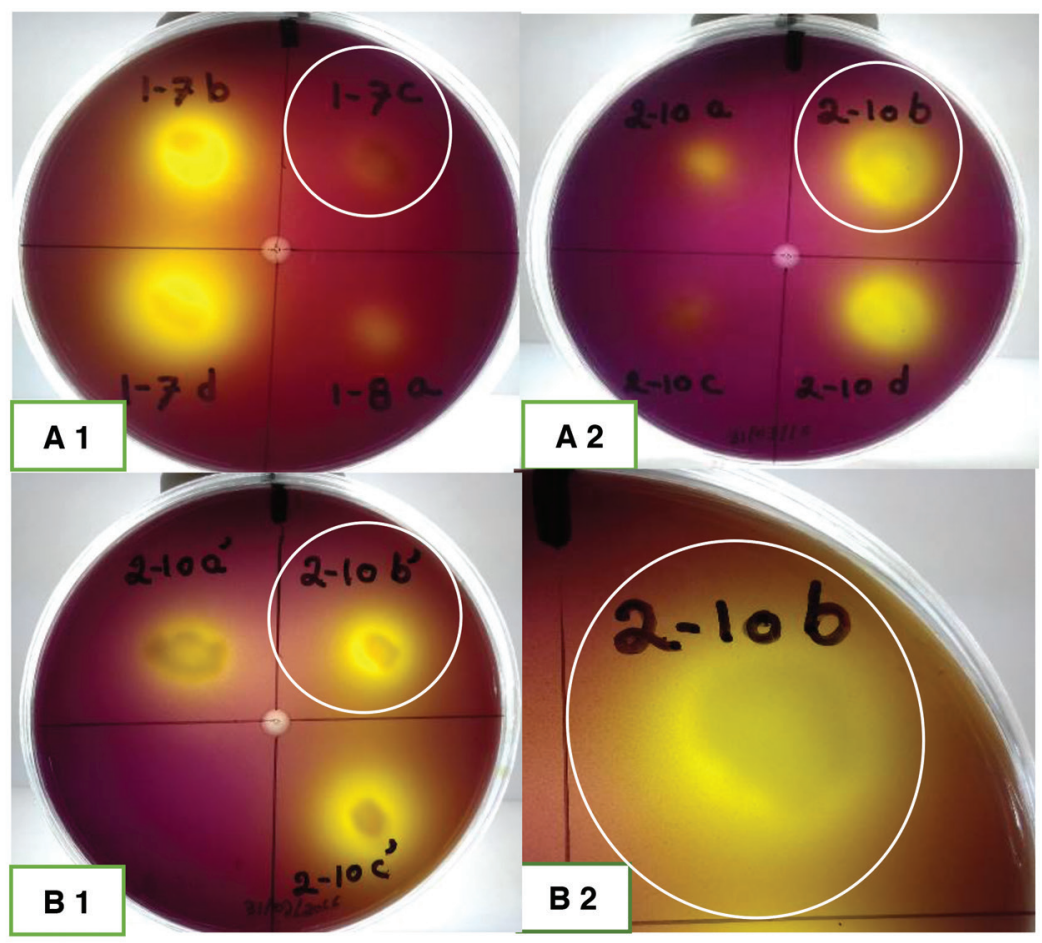

Fig. 4. Solubilización del fosfato en el medio SRS; A1 cepa 1-7c (Sinorhizobium sp.) y A2 cepa 2-10b (Bacillus megaterium) a las $48 \mathrm{~h}$ y B1 cepa 2-10bp (Burkholderia phytofirmans) y B2 cepa 2-10b (Bacillus megaterium) a las $96 \mathrm{~h}$.

Fig. 4. Phosphate solubilization in the SRS medium; A1 strain 1-7c (Sinorhizobium sp.) and A2 strain 2-10b (Bacillus megaterium) at 48h and B1 strain 2-10bp (Burkholderia phytofirmans) and B2 strain 2 -10b (Bacillus megaterium) at 96h.

aislado bacteriano Sinorhizobium sp. (Cepa 1-7c) presentó mayor cantidad de AIA en comparación con las demás bacterias. La cantidad de AIA sintetizado varía de especie a especie; por ejemplo, Tsavkelova et al. (2007) observaron que los aislados bacterianos del rizoplano y endófitos presentaron diferentes cantidades de producción de AIA $(\mu \mathrm{g} / \mathrm{ml})$ siendo Bacillus sp., la que presentó mayor producción de AIA con $58 \mu \mathrm{g} / \mathrm{ml}$. Sin embargo, Faria et al. (2013) encontraron que cepas de Paenibacillus sp., produjeron AIA en un rango de $1.50-3.63 \mu \mathrm{g} / \mathrm{ml}$. Al igual Galdiano-Júnior et al. (2011) observaron que Burkholderia sp., presentó mayor producción de AIA con 22.2 $\mu \mathrm{g} / \mathrm{ml}$, mientras que Enterobacter sp., 32.3 $\mu \mathrm{g} / \mathrm{ml}$ de AIA.

Múltiples estudios han demostrado el efecto beneficioso del AIA producido por las BPCV, incluyendo las especies de orquídeas. Faria et al. (2013) observaron que Paenibacillus macerans (1C) promovió el crecimiento de plántulas durante la aclimatación ex vitro de Cattleya loddigesii Lindl. Igualmente Galdiano-Júnior et al. (2011) reportaron que Enterobacter sp. y Bacillus sp., promovieron el crecimiento de las plántulas de Cattleya walkeriana Gardner durante la aclimatación ex vitro en invernadero. $\mathrm{Al}$ igual Tsavkelova et al. (2007b) en la inoculación de semillas de Dendrobium moschatum (Buch.-Ham.) Sw. con bacterias productoras de AIA de Sphingomonas sp. y Mycobacterium sp., presentaron una mejora en la germinación, mostrando claramente que las bacterias juegan un papel importante para la germinación in vitro. Incluso las cepas que producen menores cantidades de AIA siguen liberando continuamente este compuesto indol, por lo que, desde un punto de vista práctico, el tratamiento de las semillas de orquídeas con cepas productoras de 
IAA puede ser un método útil y ventajoso para la propagación de orquídeas in vitro (Tsavkelova et al., 2007b). Sin embargo no todas las bacterias que producen AIA estimulan la germinación de las semillas, por ejemplo se ha observado que Rhizobium sp. no promueve la germinación (Tsavkelova et al., 2007b). El AIA es el responsable de la división, elongación y estimulación del desarrollo y crecimiento de las raíces (Tsavkelova et al., 2007a y b). También estimula la germinación de las semillas y tubérculos, aumenta el desarrollo del xilema y de las raíces en la formación de raíces laterales y adventicias (Glick, 2012). Las 10 cepas bacterianas presentaron la producción de AIA, por lo que pudieran ser inoculadas en semillas, procormos y/o plántulas de orquídeas para una germinación y un desarrollo in vitro y ex vitro más rápido. Sin embargo, consideramos que las cepas bacterianas que presentaron mayor producción de AIA, merecen la atención de estudios más profundos para evaluar su real potencial como inoculantes aplicables al cultivo de la orquídea G. skinneri.

En las evaluaciones de fijación de nitrógeno las 10 bacterias tuvieron la capacidad de reducir el acetileno a etileno en las pruebas en condiciones in vitro. Estos resultados son similares a lo obtenido por Villegas-Espinoza et al. (2014) quienes observaron que Bacillus amyloliquefaciens presentó mayor reducción de acetileno con $6.28 \mathrm{nmol}$ del cultivo ${ }^{-1} \mathrm{~h}^{-1}$ en contraste con el control Azospirillum halopraeferens con $7.2 \mathrm{nmol}$ del cultivo ${ }^{-1} \mathrm{~h}^{-1}$. La bacteria Bacillus sp. presentó mayor reducción de acetileno por lo tanto se puede considerar como una posible bacteria fijadora de nitrógeno (BFN) por presentar cantidades mayores de etileno. El proceso de fijación de nitrógeno es realizado por la enzima nitrogenasa que está presente en las bacterias que fijan nitrógeno atmosférico haciendo disponible este nutriente para las plantas. Para realizar este proceso la enzima rompe el triple enlace del nitrógeno y una de las pruebas que se han utilizado en la detección de la enzima en condiciones in vitro es la prueba de reducción de acetileno a etileno que también presenta triple enlace (Hardy et al., 1968). En aquellas bacterias que tienen la capacidad de romper este enlace, serán detectados por el cromatógrafo de gases los picos correspondientes a cada compuesto, evidenciando así la participación de la enzima en la reducción de acetileno a etileno. Diversas bacterias presentes en las raíces de las orquídeas se han caracterizado mediante la detección del gen nifH que codifica para la enzima nitrogenasa en la fijación del nitrógeno (Álvarez-López et al., 2014; Yang et al., 2014; Li et al., 2017).

Las bacterias fijadoras de nitrógeno muestran resultados favorables en la germinación y desarrollo de plántulas en Prosopis chilensis (Molina) Stuntz (Villegas-Espinoza et al., 2014). Estas bacterias hacen disponible el N atmosférico para las plantas y son consideradas como BPCV por presentar funciones que favorecen la disponibilidad de nutrientes (Glick, 2012). Li et al., (2017) mencionan que las bacterias diazotrófas se encuentran presentes en la mayor parte de los tejidos aportando nitrógeno, a pesar que también se encuentran otros géneros bacterianos cumpliendo en las raíces. En ocasiones las bacterias no presentan interacciones beneficiosas con plantas debido a que las bacterias fijadoras de $\mathrm{N}_{2}$ que no forman simbiosis no son tan efectivas como las bacterias simbióticas (Álvarez-López et al., 2014). Esto se debe que las bacterias que forman nódulos en las raíces aportan mayor $\mathrm{N}$ a la planta impulsando así el crecimiento y desarrollo (Franche, Lindström y Elmerich, 2009). Las BFN encontradas pueden resultar beneficiosas para las semillas y plántulas de la orquídea $G$. skinneri, haciendo disponible el N para la planta. Muchas de estas bacterias aisladas pueden establecer una relación estrecha en las semillas o plántulas, por lo que se considera que tienen potencial para la conservación de la orquídea, principalmente por ser bacterias encontradas a partir de raíces de la misma especie.

Respecto a las bacterias que presentaron unas de las categorías establecidas ante el hongo RG26, también se han presentado en otros trabajos de orquídeas. Wang et al. (2016) observaron tres tipos de interacciones en la confrontación de hongos endófitos y bacterias 
endófitas: antagonismo, interacción positiva y letal. Tanto Wang et al. (2016) como Macedo et al. (2012) encontraron este tipo de interacción positiva donde ambos, bacteria y hongo no se afectaban entre sí, permitiendo el crecimiento del hongo sobre la colonia bacteriana; estos resultados son similares a los obtenidos en las interacciones de nuestras evaluaciones (Figura 2). También se observó un antagonismo 50-50 de las bacterias y del hongo RG26 donde ambos competían por el recurso. Macedo et al. (2012) mencionan que esto se debe a competencia por nutrientes y/o de espacio o en caso de antagonismo mutuo entre el hongo y la bacteria. En las interacciones de inhibición se observó que las bacterias inhibieron el crecimiento del hongo RG26, al que Macedo et al. (2012) obtuvieron diferentes grados de inhibición del crecimiento del hongo Colletotrichum gloeosporioides, obteniendo 8 géneros de bacterias de Burkholderia y Bacillus con alto grado de inhibición. Macedo et al. (2012) mencionan que en dicha zona de la placa Petri podría existir una concentración efectiva de metabolitos que son secretados por la bacteria antagonista hacia el medio de cultivo y por lo tanto el hongo limita su crecimiento y se desarrolla a los lados donde hay menor concentración de metabolitos. También la inoculación de bacterias en conjunto o individuales en condiciones in vitro puede producir compuestos orgánicos volátiles (COV) que pueden ejercer un efecto inhibidor en el desarrollo del hongo (VelázquezBecerra, Macías-Rodríguez, López-Bucio, Flores-Cortez, Santoyo, Hernández-Soberano, \& Valencia-Cantero, 2013). Por otro lado, Gkarmiri et al. (2015) encontraron que los hongos como Rhizoctonia solani desarrollan una amplia gama de mecanismos para defenderse durante la competencia ante el confrontamiento in vitro con Serratia proteamaculans y Serratia plymuthica. Sin embargo, las interacciones que observamos fueron solamente de manera visual y mediante la toma de datos del crecimiento del hongo hacia las bacterias; por lo tanto es importante realizar análisis más profundos para entender la fisiología de esta interacción y aclarar aspectos básicos antes de promover una posible aplicación en la práctica agronómica. No obstante, con los resultados obtenidos acerca de las interacciones positivas bacteria-hongo podemos asumir una respuesta favorable en las inoculaciones posteriores de estos microorganismos en las plantas de orquídeas para una mayor micorrización en las raíces. En este sentido, Wang et al. (2016) observaron que la planta se puede beneficiar con las inoculaciones de hongo-bacteria. De esta forma, la inoculación artificial de determinada cepa bacteriana puede ayudar la micorrización en las plantas y pudiera ser muy útil al reintroducir el material vegetal en su ambiente natural, aumentando la probabilidad de sobrevivencia, comparado con plantas no inoculadas.

En las evaluaciones de solubilización de fosfato, los resultados obtenidos muestran que la mayor parte de las bacterias aisladas fueron capaces de solubilizar el fosfato inorgánico disponible en el medio de cultivo. Los resultados obtenidos en esta evaluación son diferentes a aquellos presentados por Faria et al. (2013) donde no registraron capacidad de solubilización de fosfato inorgánico, aunque presentaron altos índices de producción de AIA. Al contrario, Álvarez-López et al. (2014) reportaron que en Vanilla planifolia Jacks. ex Andrews, las bacterias Serratia sp., y Pseudomonas koreensis presentaron mayor eficiencia en la solubilización de fosfato. Al igual, Villegas-Espinoza et al. (2014) observaron que B. amyloliquefaciens presentó la mayor solubilización, de una manera significativa $(\mathrm{P}<0.05)$ comparada con otros géneros (Kocuria polaris, Planococcus antarcticus y Rhododcoccus fascians). Vazquez, Holguin, Puente, Lopez-Cortes, \& Bashan (2000) proponen que la solubilización de fosfato se debe a la producción de ácidos orgánicos, compuestos volátiles y no volátiles de estos microorganismos, como posible mecanismo en la solubilización del fosfato de calcio insoluble. Diversas bacterias solubilizan compuestos como el fosfato tricálcico, el fosfato dicálcico, la hidroxiapatita y la roca fosfórica (Paredes-Mendoza \& Espinosa-Victoria, 2009; Corrales-Ramírez, Arévalo-Galvez, \& MorenoBurbano, 2014). Rodríguez, Fraga, Gonzalez, 
\& Bashan (2006) mencionan que algunos genes están involucrados en la solubilización de fosfatos minerales y orgánicos, así como la oxidación directa de la glucosa al ácido glucónico (GA) como mecanismo principal para la solubilización mineral de fosfato en bacterias Gram-negativas.

Muchas cepas bacterianas presentaron diferentes IS similares a los obtenidos por Corrales-Ramírez, Sánchez-Leal, Arévao-Galvez, \& Moreno-Burbano (2014). También se observa que la solubilización de fosfato no se presentó a las $46 \mathrm{~h}$, sino hasta las $96 \mathrm{~h}$. Fenómenos similares fueron observados por Corrales-Ramírez et al., (2014). Para la conservación de las orquídeas, y en el caso específico de G. skinneri, sería muy útil emplear cepas de bacterias beneficiosas que puedan ser capaces de promover mayor absorción de $\mathrm{P}$ por la planta. Considerando el caso de un cultivo in vitro a partir de semilla de esta especie con la finalidad de una reintroducción en la naturaleza, una mayor absorción de $\mathrm{P}$ implicaría para la planta un mayor vigor y una mejor aclimatación en condiciones naturales y por ende un aumento de la probabilidad de éxito en la reintroducción. Se ha reportado que cepas bacterianas que han sido aisladas de las orquídeas y puestas en contacto con semillas han presentado resultados exitosos en la germinación y la supervivencia en el proceso de aclimatación ex vitro de las orquídeas (Tsavkelova et al., 2007b; Galdiano-Júnior et al., 2011; Faria et al., 2013; Wang et al., 2016).

De las 10 cepas bacterianas seleccionadas, consideramos que Bacillus sp. puede ser usada como inoculante bacteriano en semillas y plántulas de la orquídea G. skinneri por presentar resultados beneficiosos como producción de AIA, fijación de nitrógeno, interacción positiva con el hongo micorrízico RG26 y solubilización de fosfato. Sin embargo no descartamos las demás bacterias identificadas por no presentar resultados similares a Bacillus sp., lo ideal es evaluar estas bacterias en semillas y plántulas de G. skinneri para observar cómo benefician en la germinación y desarrollo de las plántulas, así en un futuro poder implementar este mecanismo en la reintroducción de esta orquídea en su hábitat mediante la inoculación de bacterias. Este es el primer estudio específico acerca de las BPCV en la orquídea G. skinneri, subrayando la importancia de su caracterización en las raíces de la oriquídea.

Declaración de ética: los autores declaran que todos están de acuerdo con esta publicación y que han hecho aportes que justifican su autoría; que no hay conflicto de interés de cualquier tipo; y que han cumplido con todos los requisitos y procedimientos éticos y legales pertinentes. El documento firmado se encuentra en los archivos de la revista.

\section{AGRADECIMIENTOS}

Al Consejo Nacional de Ciencia y Tecnología (CONACYT), por la beca escolar no. 573959 otorgado a Trinidad Aguilar Díaz para la realización de la presente investigación.

\section{RESUMEN}

La orquídea Guarianthe skinneri está incluida en la norma NOM-059-ECOL-2010 de México como una especie amenazada. Con el fin de estudiar las BPCV (bacterias promotoras del crecimiento vegetal) en esta orquídea, se recolectaron 10 raíces de diferentes plantas para aislar bacterias asociadas a las raíces, que se analizaron mediante pruebas in vitro como: producción de AIA, fijación de nitrógeno, interacción con el hongo micorrízico Thanatephorus sp. cepa RG26 y solubilización de fosfato. De los 71 aislados bacterianos se caracterizaron 10 cepas mediante secuenciación con el marcador $16 \mathrm{~s}$ rADN y se identificaron seis cepas: Sphingomonas sp., Sinorhizobium sp., Bacillus sp., Nocardia cerradoensis, Bacillus megaterium y Burkholderia phytofirmans. Se observó que la bacteria Sinorhizobium sp. produjo mayor cantidad de AIA (69.189 $\mu \mathrm{g} / \mathrm{ml})$ y Bacillus sp. presentó mayor reducción de acetileno $(10.251 \mathrm{nmol}$ cultivo/96 h). En las interacciones de las bacterias y el hongo RG26 se presentaron cuatro categorías (sumamente positivo, positivo, antagonismo 50-50 e inhibición). En relación a la solubilización de fosfato, la bacteria Burkholderia phytofirmans presentó mayor IS a las 48 y $96 \mathrm{~h}$ con IS de 3.11 y 3.48 , respectivamente. Los resultados indican que Bacillus sp. pudiera tener las mejores características para promover el desarrollo de la orquídea $G$. skinneri mediante la inoculación de semillas y plántulas. 
Palabras clave: Bacillus sp.; antagonismo; ácido indolacético; solubilización de fosfato; fijación de nitrógeno.

\section{REFERENCIAS}

Ahemad, M., \& Kibret, M. (2014). Mechanisms and applications of plant growth promoting rhizobacteria: Current perspective. Journal of King Saud University - Science, 26(1), 1-20. DOI: 10.1016/j. jksus.2013.05.001

Álvarez-López, C., Osorio-Vega, W., Díez-Gómez, M., \& Marín-Montoya, M. (2014). Caracterización bioquímica de microorganismos rizosféricos de plantas de vainilla con potencial como biofertilizantes. Agronomía Mesoamericana, 25(2), 225-241. DOI: 10.15517/ am.v25i2.15426

Bechtel, H., Cribb, P., \& Launert, E. (1992). The manual of cultivated orchid species ( $3^{\text {rd }}$ Ed.). Massachusetts, U.S.A.: MIT Press.

Bertolini, V., Damon, A., \& Ibarra-Cerdeña, C. (2016). Atlas de las orquídeas del Soconusco: modelos digitales de nichos ambientales entre Centro y Sudamérica. Tapachula, México: El Colegio de la Frontera Sur.

Bertolini, V., Damon, A., \& Rojas-Veláquez, A. (2011). Symbiotic germination of three species of epiphytic orchids susceptible to genetic erosion, from Soconusco (Chiapas, Mexico). European Journal of Environmental Sciences, 1(2), 60-68.

Bogarín, D., \& Pupulin, F. (2007). Las orquídeas del Parque Nacional Barra Honda, Guanacaste, Costa Rica. Lankesteriana, 7(1-2), 446-449.

Carrillo, A., Puente, M., Castellanos, T., \& Bashan, Y. (1998). Aplicaciones biotecnológicas de Ecología Microbiana. Manual de laboratorio. Bogotá, Colombia: Pontificia Universidad Javeriana y Centro de Investigaciones Biológicas del Noroeste.

Chakravorty, S., Helb, D., Burday, M., Connell, N., \& Alland, D. (2007). A detailed analysis of $16 \mathrm{~S}$ ribosomal RNA gene segments for the diagnosis of pathogenic bacteria. Journal of Microbiological Methods, 69(2), 330-339. DOI: 10.1016/j.mimet.2007.02.005

Corrales-Ramírez, L., Arévalo-Galvez, Z., \& MorenoBurbano, V. (2014). Solubilización de fosfatos: una función microbiana importante en el desarrollo vegetal. Nova, 12(21), 67-79.

Corrales-Ramírez, L., Sánchez-Leal, L., Arévao-Galvez, Z., \& Moreno-Burbano, V. (2014). Bacillus: género bacteriano que demuestra ser un importante solubilizador de fosfato. Nova, 12(21), 165-178.

Dakora, F., \& Phillips, D. (2002). Root exudates as mediators of mineral acquisition in low-nutrient environments. Plant and Soil, 245(1), 35-47. DOI: 10.1023/A:1020809400075

Damon, A., \& Colín-Martínez, H. (2004). El estado actual de las poblaciones de orquídeas en la región del Soconusco, Chiapas. Amaranto. El Boletín de La Asociación de Jardines Botánicos de México, (3), 2-16.

Dressler, L., \& Higgins, E. (2003). Guarianthe, a generic name for the "Cattleya" skinneri complex. Lankesteriana, 7, 37-38.

Faria, D., Dias, A., Melo, I., \& Carvalho-Costa, F. (2013). Endophytic bacteria isolated from orchid and their potential to promote plant growth. World Journal of Microbiology and Biotechnology, 29, 217-221. DOI: 10.1007/s11274-012-1173-4

Franche, C., Lindström, K., \& Elmerich, C. (2009). Nitrogen-fixing bacteria associated with leguminous and non-leguminous plants. Plant and Soil, 321(1-2), 35-59. DOI: $10.1007 / \mathrm{s} 11104-008-9833-8$

Galdiano-Júnior, R., Pedrinho, E., Castellane, T., \& Lemos, E. (2011). Auxin-producing bacteria isolated from the roots of Cattleya walkeriana, an endangered Brazilian orchid, and their role in acclimatization. Revista Brasileira de Ciência Do Solo, 35(3), 729-737. DOI: 10.1590/S0100-06832011000300008

Gkarmiri, K., Finlay, R., Alström, S., Thomas, E., Cubeta, M., \& Högberg, N. (2015). Transcriptomic changes in the plant pathogenic fungus Rhizoctonia solani AG-3 in response to the antagonistic bacteria Serratia proteamaculans and Serratia plymuthica. BMC Genomics, 16, 630. DOI: 10.1186/s12864-015-1758-z

Glick, B. (2012). Plant Growth-Promoting Bacteria: Mechanisms and Applications. Scientifica, 2012, 1-15. DOI: 10.6064/2012/963401

Gordon, S., \& Weber, R. (1951). Colorimetric Estimation of Indoleacetic Acid. Plant Physiology, 26(1), 192-195.

Hardy, R., Holsten, R., Jackson, E., \& Burns, R. (1968) The Acetylene-Ethylene Assay for N2 Fixation: Laboratory and Field Evaluation. Plant Physiology, 43, 1185-1207. DOI: 10.1104/pp.43.8.1185

Hartmann, A., Schmid, M., van Tuinen, D., \& Berg, G. (2009). Plant-driven selection of microbes. Plant and Soil, 321(1-2), 235-257. DOI: 10.1007/ s11104-008-9814-y

Jones, K., Kobayashi, H., Davies, B., Taga, M., \& Walker, G. (2007). How rhizobial symbionts invade plants: the Sinorhizobium-Medicago model. Nature Reviews. Microbiology, 5(8), 619-33. DOI: 10.1038/ nrmicro1705

Kimura, M. (1980). A simple method for estimating evolutionary rates of base substitutions through comparative studies of nucleotide sequences. Journal of 
Molecular Evolution, 16(2), 111-120. DOI: 10.1007/ BF01731581

King, E., Ward, W., \& Raney, D. (1954). Two simple media for the desmostration of pyocyanin and fluorescin. Journal of Laboratory and Clinical Medicine, 4(2), 301-307.

Kumar, S., Stecher, G., \& Tamura, K. (2016). MEGA7: Molecular Evolutionary Genetics Analysis Version 7.0 for Bigger Datasets. Molecular Biology and Evolution, 33(7), 1870-1874. DOI: 10.1093/molbev/ msw054

Kumar, V., \& Narula, N. (1999). Solubilization of inorganic phosphates and growth emergence of wheat as affected by Azotobacter chroococcum mutants. Biology and Fertility of Soils, 28(3), 301-305. DOI: 10.1007/ s003740050497

Li, O., Xiao, R., Sun, L., Guan, C., Kong, D., \& Hu, X. (2017). Bacterial and diazotrophic diversities of endophytes in Dendrobium catenatum determined through barcoded pyrosequencing. PLoS ONE, 12(9), 1-21. DOI: 10.1371/journal.pone.0184717

López-Chávez, M., Guillén-Navarro, K., Bertolini, V., Encarnación, S., Hernández-Ortiz, M., SánchezMoreno, I., \& Damon, A. (2016). Proteomic and morphometric study of the in vitro interaction between Oncidium sphacelatum Lindl. (Orchidaceae) and Thanatephorus sp. RG26 (Ceratobasidiaceae). Mycorrhiza, 26(5), 1-13. DOI: 10.1007/ s00572-015-0676-x

Macedo, C., Martínez, H., \& Lara, R. (2012). Rizobacterias aisladas del trópico húmedo con actividad antagónica sobre Colletotrichum gloeosporioides, evaluación cuantitativa e identificación molecular. Revista Mexicana de Fitopatología, 30(1), 11-30.

Mantilla-Cardenas, M. (2007). Evaluación de la acción de un bioinoculante sobre un cultivo de crisantemo (Chrysanthemum morifolium var. yoko ono) en periodo de enraizamiento (Tesis de Licenciatura). Pontificia Universidad Javeriana, Colombia.

Paredes-Mendoza, M., \& Espinosa-Victoria, D. (2009). Organic Acids Produced by Phosphate Solubilizing Rhizobacteria: A Critical Review. Terra Latinoamericana, 28(1), 61-70.

Prashar, P., Kapoor, N., \& Sachdeva, S. (2014). Rhizosphe$r e$ : Its structure, bacterial diversity and significance. Reviews in Environmental Science and Biotechnology, 13(1), 63-77. DOI: 10.1007/s11157-013-9317-z

R Core Team. (2013). R: A language and environment for statistical computing. R Foundation for Statistical Computing, Vienna, Austria. Retrieved from https:// www.R-Project.org

Rennie, R. (1981). A single medium for the isolation of acetylene-reducing (dinitrogen-fixing) bacteria from soils. Canadian Journal of Microbiology, 27, 8-14. Retrieved from http://www.nrcresearchpress.com/ DOI/abs/10.1139/m81-002

Rodríguez, H., Fraga, R., Gonzalez, T., \& Bashan, Y. (2006). Genetics of phosphate solubilization and its potential applications for improving plant growthpromoting bacteria. Plant and Soil, 287(1-2), 15-21. DOI: $10.1007 / \mathrm{s} 11104-006-9056-9$

Semarnat. (2010). Norma oficial Mexicana NOM-059-SEMARNAT-2010. Diario Oficial, 78.

Solano-Gómez, R., Damon, A., Cruz-Lustre, G., Jiménez-Bautista, L., Avendaño-Vázquez, S., Bertolini, V., Rivera-García, R., \& Cruz-García, G. (2016). Diversity and distribution of the orchids of the Tacaná-Boquerón region, Chiapas, Mexico. Botanical Sciences, 94(3), 625-656. DOI: 10.17129/botsci.589

Sundara-Rao, W., \& Sinha, M. (1963). Phosphate dissolving microorganisms in the soil and rhizosphere. The Indian Journal of Agricultural Sciences, 33(4), 272-278. Retrieved from https://scholar.google.es/ scholar?q=related:MYpFGIALEgkJ:scholar.google. $\mathrm{com} / \& \mathrm{hl}=\mathrm{es} \&$ as $\mathrm{sdt}=0,5 \# 0$

Tsavkelova, E., Cherdyntseva, T., \& Netrusov, A. (2005). Auxin production by bacteria associated with orchid roots. Microbiology, 74(1), 46-53. DOI: 10.1007/ s11021-005-0027-6

Tsavkelova, E., Cherdyntseva, T., Botina, S., \& Netrusov, A. (2007a). Bacteria associated with orchid roots and microbial production of auxin. Microbiological Research, 162, 69-76. http://DOI.org/10.1016/j. micres.2006.07.014

Tsavkelova, E., Cherdyntseva, T., Klimova, S., Shestakov, A., Botina, S., \& Netrusov, A. (2007b). Orchidassociated bacteria produce indole-3-acetic acid, promote seed germination, and increase their microbial yield in response to exogenous auxin. Archives of Microbiology, 188, 655-664. http://DOI.org/10.1007/ s00203-007-0286-x

Tsavkelova, E., Cherdyntseva, T., Lobakova, E., Kolomeitseva, G., \& Netrusov, A. (2001). Microbiota of the Orchid Rhizoplane. Microbiology, 70(4), 492497. DOI: $10.1023 / \mathrm{A}: 1010402715376$

Tsavkelova, E., Lobakova, E., Kolomeitseva, G., Cherdyntseva, T., \& Netrusov, A. (2003). Associative Cyanobacteria Isolated from the roots of epiphytic orchids. Microbiology, 72(1), 92-97. DOI: 10.1023/A:1022238309083

Vargas-Zamora, J., \& Gómez-Laurito, J. (2005). Algunas plantas en billetes, boletos de café y cafetales de Costa Rica (1836-2004). Lankesteriana, 5(2), 141-158.

Vazquez, P., Holguin, G., Puente, M., Lopez-Cortes, A., \& Bashan, Y. (2000). Phosphate-solubilizing 
microorganisms associated with the rhizosphere of mangroves in a semiarid coastal lagoon. Biology and Fertility of Soils, 30(5-6), 460-468. DOI: 10.1007/ s003740050024

Velázquez-Becerra, C., Macías-Rodríguez, L., LópezBucio, J., Flores-Cortez, I., Santoyo, G., Hernández-Soberano, C., \& Valencia-Cantero, E. (2013). The rhizobacterium Arthrobacter agilis produces dimethylhexadecylamine, a compound that inhibits growth of phytopathogenic fungi in vitro. Protoplasma, 250(6), 1251-1262. DOI: 10.1007/ s00709-013-0506-y

Villegas-Espinoza, J., Rueda-Puente, E., Murillo-Amador, B., Puente, M., Ruiz-Espinoza, H., Zamora-Salgado, S., \& Beltran, F. (2014). Bacterias promotoras de crecimiento de plantas autóctonas y su efecto en Prosopis chilensis (Molina) Stunz. Revista Mexicana de Ciencias Agrícolas, 5(6), 1041-1053.

Wang, X., Yam, T., Meng, Q., Zhu, J., Zhang, P., Wu, H., ... Song, X. (2016). The dual inoculation of endophytic fungi and bacteria promotes seedlings growth in Dendrobium catenatum (Orchidaceae) under in vitro culture conditions. Plant Cell, Tissue and Organ Culture (PCTOC), (1). DOI: 10.1007/ s11240-016-1021-6

Weisburg, W., Barns, S., Pelletier, D., \& Lane, D. (1991). 16S Ribosomal DNA Amplification for Phylogenetic Study. Journal of Biotechnology, 173(2), 697-703.

Yang, S., Zhang, X., Cao, Z., Zhao, K., Wang, S., Chen, M., \& Hu, X. (2014). Growth-promoting Sphingomonas paucimobilis ZJSH1 associated with Dendrobium officinale through phytohormone production and nitrogen fixation. Microbial Biotechnology, 7(6), 611-620. DOI: 10.1111/1751-7915.12148

Yoder, J., Zettler, L., \& Stewart, S. (2000). Water requirements of terrestrial and epiphytic orchid seeds and seedlings, and evidence for water uptake by means of mycotrophy. Plant Science, 156(2), 145-150.

Zambrano-Ramos, E., Salgado-Jiménez, T., \& HernándezTapia, A. (2007). Estudio de bacterias asociadas orquídeas (Orchidaceae). Lankesteriana, 7(1-2), 322325. DOI: 10.15517/lank.v7i1-2.19556 


\section{APÉNDICE 1}

Temperatura del horno en el cromatógrafo de gases

\section{APPENDIX 1}

Oven temperature in the gas chromatograph

\begin{tabular}{cccc} 
& Rampa $\left({ }^{\circ} \mathrm{C} / \mathrm{min}\right)$ & Temperatura $\left({ }^{\circ} \mathrm{C}\right)$ & Isotérmico $(\mathrm{min})$ \\
Inicial & 0.0 & 35 & 2.00 \\
1 & 10.0 & 85 & 0.00 \\
2 & 20.0 & 110 & 1.00 \\
\hline
\end{tabular}

\section{APÉNDICE 2}

Características de las cepas en las pruebas para considerar como BPCV

\section{APPENDIX 2}

Evaluation of strains in tests to be considered as BPCV

\begin{tabular}{|c|c|c|c|c|c|c|c|}
\hline \multirow[t]{2}{*}{ No } & \multirow[t]{2}{*}{ Cepa } & \multirow{2}{*}{$\begin{array}{c}\text { Ácido indol } \\
\text { acético (AIA)• } \\
\mu \mathrm{g} / \mathrm{ml} .\end{array}$} & \multirow{2}{*}{$\begin{array}{c}\text { Análisis de } \\
\text { acetileno• } \\
\text { nmol }\end{array}$} & \multirow{2}{*}{$\begin{array}{c}\text { Interacción } \\
\text { RG26* }\end{array}$} & \multicolumn{2}{|c|}{ Índice de solubilización (IS) $\dagger$} & \multirow[t]{2}{*}{ Identificación molecular } \\
\hline & & & & & IS a $48 \mathrm{hr}$ & IS a $96 \mathrm{hr}$ & \\
\hline 1 & $1-4 c$ & $15.69 \pm 0.64$ & $4.958 \pm 1.49 \mathrm{abc}$ & - & $0.00 \pm 0$ & $0.00 * \pm 0$ & Sphingomonas sp. \\
\hline 2 & $1-6 a$ & $14.15 \pm 0.35$ & $5.702 \pm 1.42 \mathrm{abc}$ & 0 & $2.22 \pm 0.07$ & $2.38 \pm 0.02$ & SR \\
\hline 3 & $1-7 \mathrm{c}$ & $69.18 \pm 0.97$ & $1.637 \pm 1.11 \mathrm{bc}$ & 0 & $2.24 \pm 0.04$ & $2.34 \pm 0.03$ & Sinorhizobium sp. \\
\hline 4 & $1-10 \mathrm{~d}$ & $10.18 \pm 0.33$ & $10.251 \pm 7.98 \mathrm{a}$ & ++ & $0.00 \pm 0$ & $2.31 \pm 0.004$ & Bacillus sp. \\
\hline 5 & $2-6 \mathrm{~d}$ & $13.06 \pm 0.34$ & $4.570 \pm 2.10 \mathrm{abc}$ & + & $2.15 \pm 0.04$ & $2.29 \pm 0.09$ & SR \\
\hline 6 & $2-7 \mathrm{a}$ & $11.68 \pm 0.45$ & $2.045 \pm 0.62 \mathrm{bc}$ & ++ & $0.00 \pm 0$ & $0.00 \pm 0$ & Nocardia cerradoensis \\
\hline 7 & $2-8 d$ & $13.19 \pm 0.11$ & $6.803 \pm 0.83 \mathrm{ab}$ & + & $2.42 \pm 0.04$ & $2.45 \pm 0.03$ & SR \\
\hline 8 & $2-9 b$ & $11.20 \pm 0.21$ & $5.445 \pm 0.89 \mathrm{abc}$ & 0 & $2.60 \pm 0.06$ & $2.72 \pm 0.03$ & SR \\
\hline 9 & $2-10 b$ & $10.50 \pm 0.13$ & $3.405 \pm 62.65$ & + & $2.66 \pm 0.01$ & $2.84 \pm 0.02$ & Bacillus megaterium \\
\hline 10 & $2-10 b p$ & $15.95 \pm 0.05$ & $2.619 \pm 1.98 \mathrm{abc}$ & 0 & $3.11 \pm 0.11$ & $3.48 \pm 0.03$ & Burkholderia phytofirmans \\
\hline 11 & $\mathrm{C}+$ & NA & Sm4.920 $1.82 \mathrm{abc}$ & RG26 & NA & NA & \\
\hline 12 & $\mathrm{C}-$ & $6.17 \pm 0.03$ & $0.000 \pm 0.000 \mathrm{c}$ & NA & NA & NA & \\
\hline
\end{tabular}

Valores promedio de tres repeticiones y el error estándar ( \pm ), C-: Control negativo usado, sin cultivo bacteriano, C+: control positivo Sinorhizobium meliloti 1021 (Sm). La cepa 2-10b no se tomó en cuenta en los análisis estadísticos de acetileno, los grupos con letras diferentes indican diferencia significativa $(\mathrm{P}<0.05)$. RG26: Control positivo, hongo micorrízico RG26 sin cepa bacteriana $(\mathrm{C}+)$.

$\dagger$ Valores promedio de cuatro repeticiones y error estándar ( \pm ). 0.00: cepas que crecieron en el medio de cultivo, pero no presentaron solubilización de fosfato o que la presentaron después de las $48 \mathrm{~h}$.

NA: sin controles y SR: no se logró identificación por secuencia 16s. 